\title{
Chylothorax, CTCAE
}

National Cancer Institute

\section{Source}

National Cancer Institute. Chylothorax, CT CAE. NCI Thesaurus. Code C58027.

A disorder characterized by milky pleural effusion (abnormal collection of fluid) resulting from accumulation of lymph fluid in the pleural cavity. 